\title{
ESOPHAGEAL AND OTHER LEADS IN POSTERIOR CARDIAC INFARCTION
}

\author{
BY \\ SAMUEL ORAM, Clinical Assistant to Dr. John Parkinson, National Heart Hospital, 1947-50, \\ MARY HOLT, AND TERENCE EAST \\ From the Cardiological Department, King's College Hospital
}

Received January 29, 1951

In a patient complaining of cardiac pain, the presence of a negative initial ventricular deflection ( $Q$ or QS) along with a negative $T$ wave in standard lead III, arouses suspicions of the presence of an ischæmic lesion at the back of the left ventricle. Difficulty may arise since a heart lying transversely may produce a similar curve. The diagnosis of an infarct may be supported by a $Q$ wave and negative $T$ wave in lead II (Bayley, 1939), but these confirmatory changes are not always seen (Nyboer, 1941).

The object of this investigation was to see if any help could be obtained from a lead in the œsophagus at the level of the ventricles (EV) in assessing the importance of QS and negative $\mathrm{T}$ in lead III. As the negative potential of the unipolar lead from the left foot (VF) largely determines the negative features seen in II and III, this lead (VF) was also considered. Further, we have tried to estimate the value of the deep epigastric (DE) lead and a back-foot (BF) lead described by Lian et al. (1945) in this problem. It should be noted that ventricular potentials are really recorded only from the stomach, according to Deglaude and Laubry (1949), but the letters EV are retained for an œsophageal lead; although gastro-œsophageal would be more correct.

\section{Method AND TeChNiQue}

Detailed anatomical relationships of the œsophagus are given in the papers of Brown (1936) and Deglaude and Laubry (1939), and until recently it has been assumed that the lower end of the osophagus is posterior to the left ventricle; but Kistin et al. (1950) have produced convincing electrocardiographic evidence that it may occasionally lie over the right ventricle.

Our technique was as follows. The electrode was smooth and olive shaped, half an inch in length and one-quarter of an inch at its greatest diameter, and was composed of pure tin which Deglaude and Laubry (1939) consider to be the least polarizable metal available. The tin was moulded around one end of a three-foot length of stranded copper wire, thus minimizing the risk of fracture at the junction of lead and electrode. The lead was rendered semi-rigid by passing the wire through close fitting rubber tubing, onesixth of an inch in external diameter. The lower end of the tubing fitted over the narrow neck of the electrode to give a smooth contour. One-centimetre intervals were marked on the rubber tubing by means of silver nitrate, beginning at $20 \mathrm{~cm}$. from the electrode and ending at the $60-\mathrm{cm}$. mark. Silver nitrate was chosen to withstand repeated boiling during sterilization of the lead. In most cases it was found helpful to use a local anæsthetic, any dentures being first removed. The fauces, soft palate and posterior pharyngeal wall were sprayed with a solution of 2 per cent amethocaine containing one part in four of $1: 1000$ adrenaline. In view of the slight risk of sensitivity reaction no patient received more than one ml. of the amethocaine solution, and pentothal and coramine were kept at hand during the procedure, although in fact they were never required. The electrode, lubricated with liquid paraffin, was then placed on the back of the tongue. If the patient was able to relax the pharynx the operator could guide the lead swiftly downwards with minimal discomfort. However, the majority of patients were unable to achieve the necessary relaxation, and the lead had to be passed more slowly aided by active swallowing movements. Any attempt on the part of the operator to pass the lead in the absence of complete pharyngeal relaxation resulted in coiling 
of the tube within the pharynx with the production of a severe bout of coughing. It was in this group of patients that considerable discomfort arose owing to prolonged stimulation of the cough and vomiting reflexes. Nausea and retching could often be overcome by deep inspiration. Brown (1936) pointed out that at about $30 \mathrm{~cm}$. from the incisors the esophagus lies close to the bifurcation of the trachea and delay in passing the electrode at this level provokes coughing. When coughing occurred it was important to check the level of the electrode before taking further records as there might be much displacement.

In the course of recording 150 gastro-øesophageal cardiograms we failed to pass the lead on thirteen occasions, but in over 80 per cent of the successful ones the procedure entailed appreciable discomfort such as retching, coughing or failure to swallow the lead at the first attempt. It was not without good reason that Cremer (1906) employed a professional sword swallower in his early experiments with this method of investigation. In spite of the discomfort that is often caused none of our patients was any the worse, although Katz (1950) has expressed fears to the contrary.

Most authorities now agree that fluoroscopic control of the position of the electrode is essential, and our experience amply confirms this view. The right anterior oblique position was selected since a hypertrophied left ventricle might obscure the view of the electrode in the left anterior oblique position. It was impossible to relate the position of the electrode to particular parts of the individual cardiac chamber with any degree of accuracy; we, therefore, noted the depth to which the electrode had to be passed so that its tip should rest at the level of the lower cupola of the diaphragm during halted expiration. All recordings from below that arbitrary, but easily determined, level were taken to be of ventricular origin. The electrode was then passed down into the stomach, and six unipolar recordings were made as it was withdrawn. Three of the records were taken from below the level of the lower cupola, one at that level, and two above it.

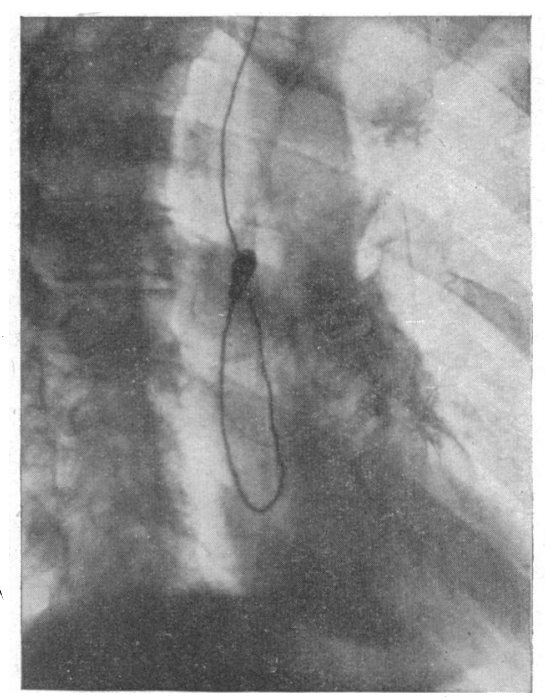

Fig. 1.-A lead curled up in the œesophagus.

The recordings were made from sites $2 \mathrm{~cm}$. apart, in halted expiration, and the patient was requested not to swallow to avoid interference from respiratory and esophageal movements. We did not find it was necessary or practical to keep the patient in the sitting position for both screening and cardiography examinations as suggested by Deglaude and Laubry (1949) for there was never any indication that the electrode changed position.

On several occasions on placing the patient behind the X-ray screen it was found that the distal portion of the lead was bent back upon itself, the electrode thus lying at a much higher level than the tube markings at the teeth indicated (Fig. 1). In the absence of fluoroscopic control this fault might pass undetected with consequent misinterpretation of the records. In several cases in which this kinking of the lead occurred it was corrected without withdrawing the lead by passing the looped portion down into the stomach where it then uncurled.

Before leaving, the patient should be warned not to take any food or drink for a period of two hours since the oral anæsthesia may persist for that time. One of our control cases developed a painful palatal burn as a result of failure to observe this precaution.

\section{Selection of Cases and Leads Recorded}

We investigated 150 cases, but 24 of these were rejected, some of the early gastro-œsophageal tracings being technically unsatisfactory and the records in others being incomplete. The series analysed therefore consisted of 126 cases. In each a full history was taken, including details of recent administration of digitalis, and the subject was examined clinically, fluoroscopically and cardiographically. From each subject twenty leads were recorded, namely the six osophageal tracings described above, the three standard leads, the three augmented unipolar limb leads, the six unipolar chest leads, a deep epigastric lead (DE) and a back foot-lead (BF). In recording the deep epigastric lead, the unipolar exploring electrode was pressed deep into the epigastrium, one inch to the left of the midline during halted expiration, and was directed as far as possible toward the inferior surface of the heart. Lead BF is bipolar, the exploring electrode being placed midway 
between the vertebral border of the left scapula and the spine, and the breadth of two fingers above the inferior angle of the scapula; the indifferent electrode is connected to the left leg.

Our first object was to determine the form and variations of the normal gastro-øsophageal cardiograms as recorded by our technique, and for this purpose we examined 28 cases, all without any history of cardiovascular disease and normal on clinical, fluoroscopic and cardiographic examination. The average age was 34 , the youngest was 21 , and the oldest 60 years old.

We next examined 27 cases in whom posterior cardiac infarction had occurred. Diagnosis was based on the clinical picture and on the cardiograms taken shortly after infarction which showed a QIII TIII curve, QII being present and TII either inverted or flat. In each case lead VF contributed to these appearances. The possibility of pulmonary embolism simulating posterior infarction in leads II and III was rendered unlikely by the presence of a pathological Q wave in VF (Goldberger, 1949). The majority of our records were made several months after infarction had occurred, but in one case only two days had elapsed, the longest interval being three and a half years. Only one case in this group was receiving digitalis and obvious RS-T segment change was present. Since the investigation began two patients have died and in both the diagnosis of posterior infarction was confirmed at autopsy.

The remainder of the series was divided into three groups (Table I): namely 42 patients in whom an equivocal standard lead III was associated with a history of cardiac pain; 19 in whom equivocal changes in lead III were unaccompanied by cardiac pain, although generally some cardiac abnormality was present, usually hypertension; and finally, 10 patients in whom there was considerable left ventricular enlargement but no history of cardiac pain.

\section{RESULTS}

Owing to lack of space, it is not possible to reproduce full details of our protocols, but an analysis is shown in Table I. Before considering our results, we must describe briefly the variation in form of the normal gastro-œsophageal cardiogram at different levels. We would also draw attention to the various artefacts encountered.

The usual form of the normal gastro-œsophageal cardiogram at different levels is now well known (Fig. 2), but the range of the normal, particularly at ventricular levels, remains to be decided. When the electrode is above the auricles a tiny $R$ wave precedes a predominantly negative $Q R S$ complex and the T wave is inverted (Fig. 2A). Such an appearance indicates that the electrode is receiving potentials from the cavity of the right ventricle. At the auricular level (Fig. 2B) the $P$ wave is characterized by a sharp intrinsic deflection. Normally this is only recorded at auricular levels, and no curve showing such an appearance may safely be interpreted as being of ventricular origin. The biphasic QRS complex and the deeply inverted T wave represent mixed potentials derived from the cavity and epicardium of the left ventricle. Below the auricular, but above the ventricular level, is a region usually referred to as the transitional zone: it is important because a record taken from this region may be wrongly assumed to be of ventricular origin and then disease will be diagnosed when none is present. The intrinsic deflection of the $P$ wave is no longer distinct, but the form of the $Q R S$ and $T$ wave still resembles that of the auricular level although inversion of the $T$ wave is less deep and the height of $R$ increases in proportion to the depth of $Q$ (Fig. 2C). At ventricular level (Fig. 2D) the $P$ wave intrinsic deflection is lost, a tiny $Q$ wave precedes a tall $R$ wave, and the $T$ wave is almost always upright. As Burchell (1948) pointed out, the close similarity between the normal ventricular complexes at atrial levels and ventricular complexes characteristic of posterior infarction at infraatrial levels may make interpretation difficult. This may explain why Kistin et al. (1950) in a recent study of 50 normal subjects found that 11 had diphasic $T$ waves and one had a frankly negative $T$ wave. $Q$ and $Q R$ deflections seemingly characteristic of atrial levels may sometimes persist 


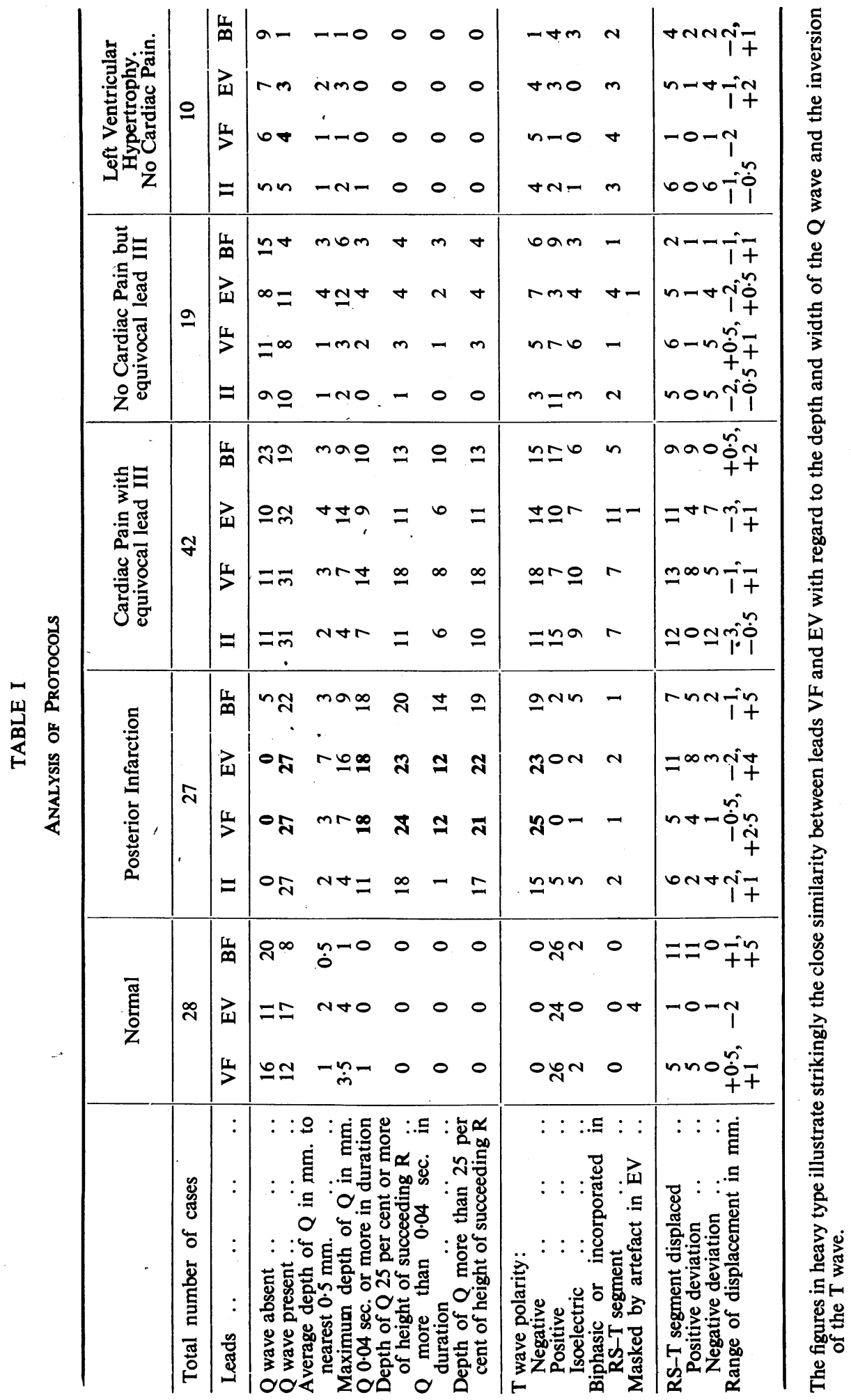


(A)

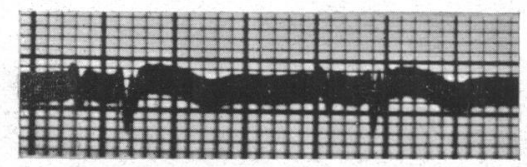

(B)

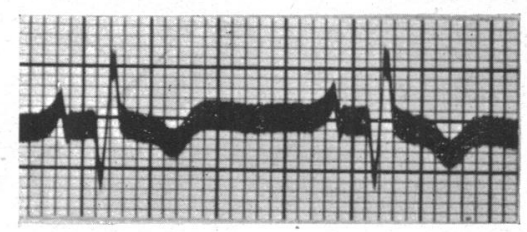

(C)

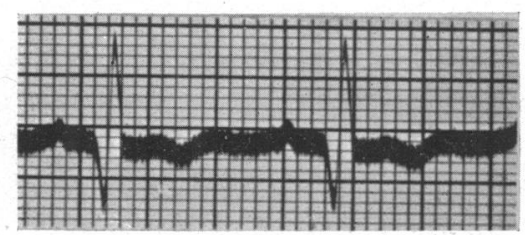

(D)

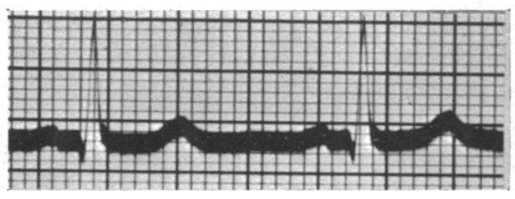

(A)

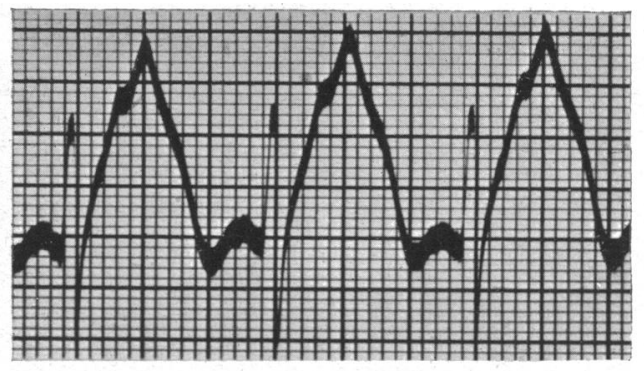

(B)

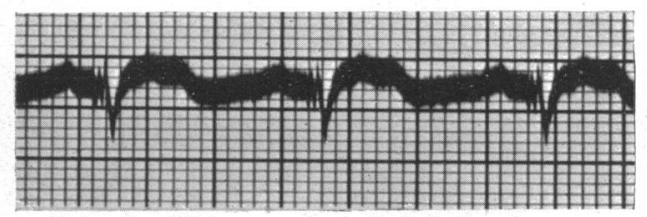

(C)

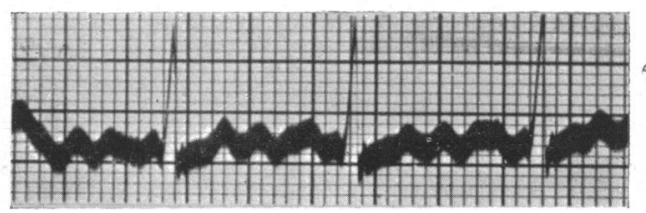

FIG. 3.-Artefacts in gastro-œsophageal records. (A) Gross displacement of the base-line syncronous with the heart beat. (B) An appearance simulating RS-T segment elevation recorded from ventricular level in a normal subject. (C) Base-line oscillation resembling auricular flutter or fibrillation in a normal subject.

below the region where the $P$ wave no longer shows an intrinsic deflection. It is evident that the extent of the transitional zone requires further study. Unfortunately, as pointed out by Bain (1950), high posterior infarcts are near this transitional zone in which a ventricular $Q$ and negative $T$ are normal findings. Deglaude and Laubry (1949) are of the opinion that the $Q$ wave in normal gastric tracings does not exceed $3 \mathrm{~mm}$. in depth or $0.03 \mathrm{sec}$. in duration, and that in pathological curves the minimum depth of $Q$ is $4 \mathrm{~mm}$. and the duration at least $0.04 \mathrm{sec}$., but we have found exceptions to this statement in both normal and abnormal patients.

From these remarks it follows that particular care should be exercised in interpreting curves taken from the upper ventricular levels: the variability of the œsophageal electrocardiogram is such that no firm diagnosis of high posterior infarction should be made from these records alone.

Artefacts in gastro-cesophageal leads. Artefacts have been a source of difficulty and may be so great as to make interpretation of the curves impossible. In our records the RS-T segment and the T wave were distorted more often than the QRS complex. Recently Scherlis et al. (1950) have introduced a condenser-resistance filter between the electrode and the amplifier input which reduces low frequency gastric, œsophageal, and diaphragmatic potentials without interfering with the detail and timing of the record. The sudden swing of the fibre, thought to be associated with the polarization effect of regurgitated gastric hydrochloric acid (Brown, 1936), was not encountered with our technique. Provided recordings were made in halted expiration, phasic deviation of the base line 
did not occur. However, many of our curves were marred by an oscillation of varying amplitude occurring synchronously with the heart beat, which as far as we know has not been mentioned elsewhere. This displacement of the fibre (Fig. 3A) usually occurs within $4 \mathrm{~cm}$. of the diaphragm level and was equally common above and below it. Mechanical displacement of the electrode by the contracting ventricle seemed a possible explanation, but against this was the fact that it occurred in only 10 per cent of the cases with a hypertrophied left ventricle as opposed to 57 per cent. of the normal controls. Bizarre modification of the $\mathrm{T}$ wave was a common feature in the series with ventricular hypertrophy. An appearance that simulates elevation of the RS-T segment may be recorded at ventricular levels in normal subjects (Fig. 3B), and occasionally oscillation of the baseline may superficially resemble auricular flutter or fibrillation (Fig. 3C).

\section{The Gastro-cesophageal Cardiogram at Ventricular LeVels}

(a) Normal cases (28). In all records the depth of $\mathrm{Q}$ was taken as the distance from the lower border of the base-line to the nadir, and the width was measured at the upper border of the base-line. Amplitudes were estimated to the nearest $0.5 \mathrm{~mm}$. and corrected for standardization, and time intervals were estimated to the nearest $0.01 \mathrm{sec}$. The average of all the complexes on the standard Cambridge film, usually six or seven, was estimated. Although in one case the $Q$ wave reached a depth of $4 \mathrm{~mm}$., the average was only $2 \mathrm{~mm}$., and in 11 cases $Q$ was entirely absent. In no case did the depth of $Q$ exceed one-quarter of the height of the succeeding $R$ wave, and the $Q$ wave was always less than $0.04 \mathrm{sec}$. in duration. In 27 of the 28 cases there was no deviation of the RS-T segment, but in one it was depressed $2 \mathrm{~mm}$.

The T wave was seen to be upright in all cases,. except in four obscured by artefacts. The QRS complex showed a QR pattern in all but two cases in which there was an RS curve, and these were the only two in which the cardiac posjtion was electrically horizontal. The level of the diaphragm recorded on screening varied between 38 and $51 \mathrm{~cm}$. from the incisor teeth, the average being $45 \mathrm{~cm}$. The ventricular levels ranged from 42 to $54 \mathrm{~cm}$. The actual average ventricular level was really "slightly higher than this, because in selecting the tracings for analysis, owing to artefacts, it was sometimes necessary to disregard the tracing below the last one showing an auricular intrinsic deflection in favour of one from a still lower level. The average diaphragmatic level in this series is appreciably lower than the level of $40 \mathrm{~cm}$. given in most anatomical descriptions, averaging $45.5 \mathrm{~cm}$. in the hearts that were electrically vertical, and $45 \mathrm{~cm}$. in the horizontal hearts.

(b) Posterior infarction cases (27). The Q wave was present in all 27 cases, the average depth being $7 \mathrm{~mm}$. It was $0.04 \mathrm{sec}$. or more in duration in 18, and the depth was one-quarter or more of the height of the succeeding $R$ wave in 23 cases. However, in 4 cases the $Q$ wave was less than $3 \mathrm{~mm}$. in depth and in two of these was also less than one-quarter of the $R$ wave and less than $0.04 \mathrm{sec}$. in duration. The $T$ wave was inverted in 23 of the 27 cases and isoelectric or diphasic in the remainder. Although the criteria for the differentiation of normal from abnormal $\mathrm{Q}$ waves vary (vide infra), the $\mathrm{Q}$ waves in two of our cases could not be regarded as in any way abnormal, yet in one of them necropsy revealed an extensive healed subendocardial infarct $3 \mathrm{~cm}$. in width and involving the whole length of the posterior wall of the left ventricle from apex to base: $Q$ in this particular case was hardly discernible (Fig. 4). Burchell (1948) is of the opinion that the œsophageal leads at ventricular levels may sometimes be normal even when the heart is known to contain a scar in the posterior wall of the left ventricle. On the other hand, in another case that at necropsy had a very large patch of old fibrosis occupying the posterior wall of the heart and undergoing some aneurysmal dilatation, the lower esophageal leads (EV 42 and EV 44) strongly suggested that the infarct was transmural, but neither lead VF nor BF were as informative (Fig. 5).

In cases of posterior infarction, lead VF is closely similar to lead EV (Table I). Every case showed a $Q$ wave in both these leads and in 18 of them the $Q$ wave was 0.04 sec. or more in duration. 

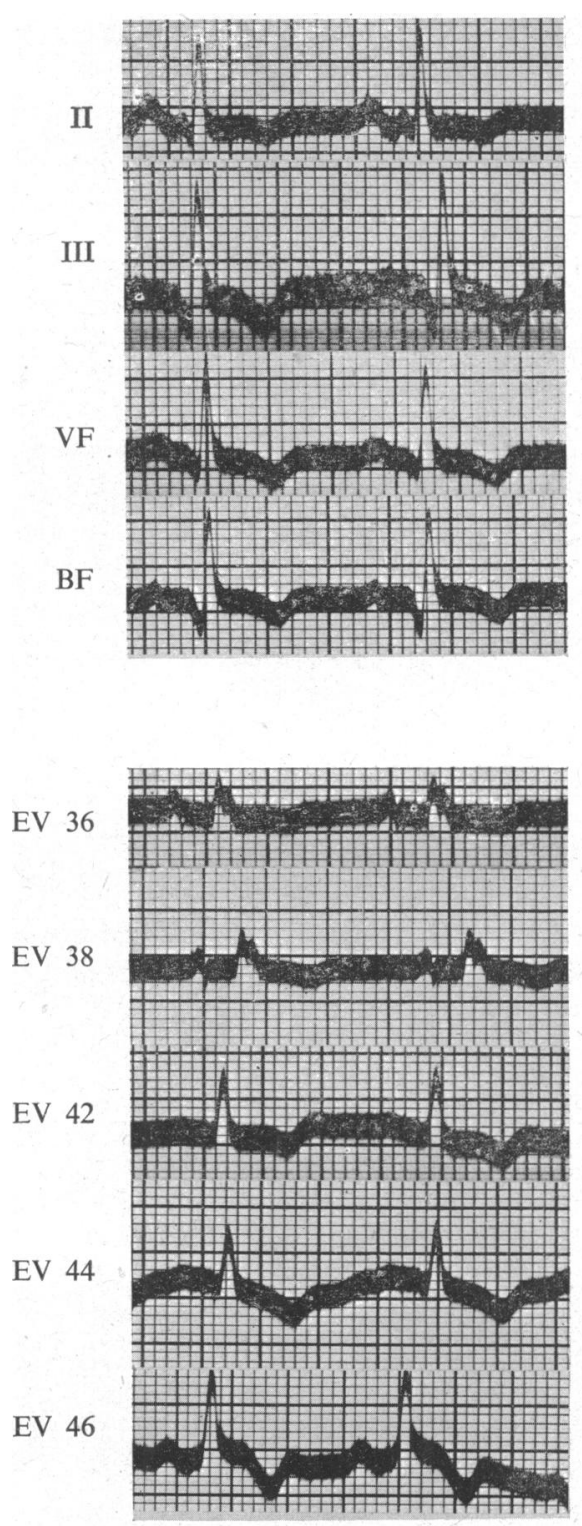

Fig. 4.-Cardiogram recorded eleven months before death in a man, aged 51 years. There are no abnormal $Q$ waves in the gastrocesophageal curves from ventricular levels in spite of the presence of an extensive healed sub-endocardial infarct involving the whole length of the posterior wall of the left ventricle.
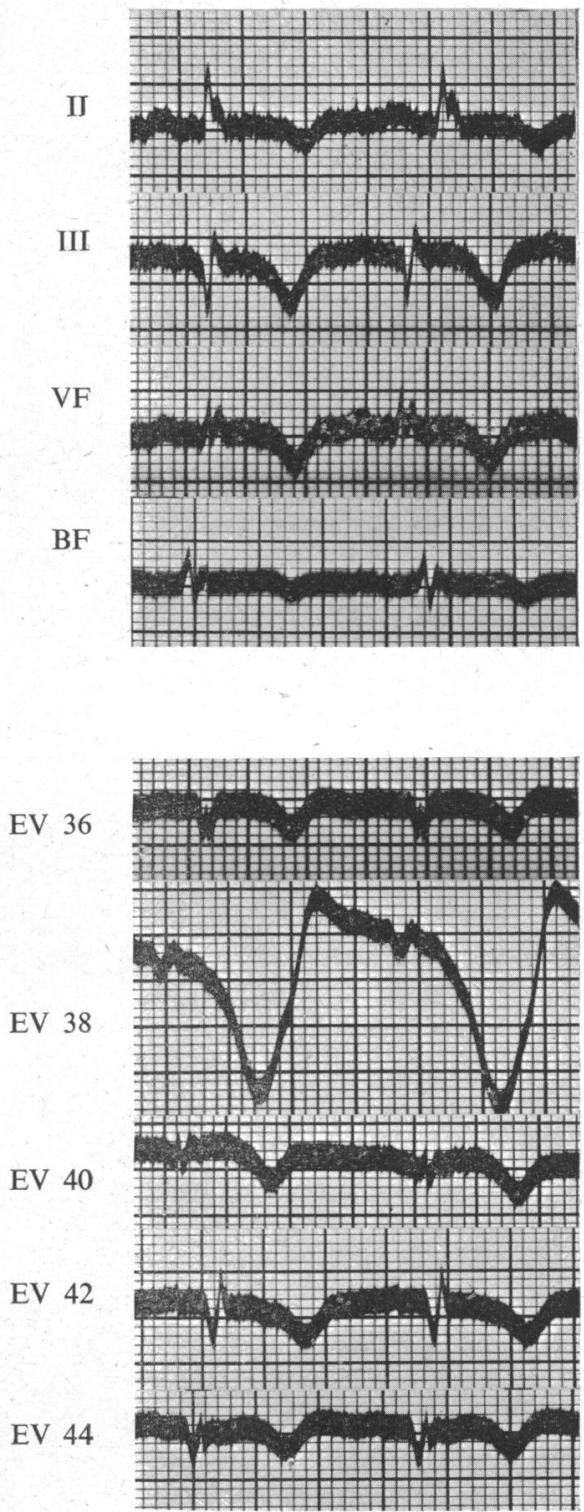

Fig. 5.-Cardiogram recorded six months before death in a woman, aged 57 . The œsophageal cardiogram at 42 and 44 centimetres from the incisor teeth is diagnostic of transmural infarction which was confirmed at necropsy. Leads VF and BF are not so informative. 
Lead VF in 24 cases showed the depth of $Q$ to be one-quarter or more of the height of the succeeding $R$ wave, as compared with 23 cases in lead $E V$.

$(c)$ and $(d)$ Cases with an equivocal lead III with cardiac pain (42) and without cardiac pain (19). It was hoped that in these two groups, each with an equivocal lead III, help would be derived from the asophageal lead. It was, in fact, the main object of the investigation. However, of the 42 cases, only 9 were considered to show posterior infarction as judged by the presence of a $Q$ wave $0.04 \mathrm{sec}$. or more in duration in œsophageal leads. Taking the same criterion for lead VF, 14 such cases were diagnosed. If the width of $Q$ was ignored, and the presence of infarction based on its depth only, namely one-quarter or more of the height of the succeeding $R$ wave, then the number of posterior infarcts revealed by œsophageal leads rose to 11 ; compared with 18 diagnosed by lead VF. It would thus appear that in any patient with chest pain and an equivocal lead III, lead VF is rather more likely to confirm or refute the presence of posterior infarction than is any œsophageal lead at ventricular levels.

Of the 19 subjects with no suspicion of cardiac pain yet with lead III suggestive of infarction, the œsophageal lead apparently confirmed the presence of posterior infarction in four, but in only three of these was a posterior infarct suggested by lead VF.

Thus, no real help was obtained from study of the osophageal leads in those very cases in which such leads might have been most helpful, namely, those in which the interpretation of lead III was in doubt. Lead VF in fact proved somewhat superior both in confirming and disproving the presence of posterior infarction.

(e) Cases with left ventricular hypertrophy (10). Nyboer (1941) reported that the presence of left ventricular hypertrophy may modify the QRS complex in the esophageal lead and cause $T$ inversion. Gastro-œsophageal leads were therefore taken in 10 cases showing much left ventricular hypertrophy and giving no history of cardiac pain. Q waves were present in three, but the maximum depth was $3 \mathrm{~mm}$., and in none did the duration reach $0.04 \mathrm{sec}$. nor the depth one-quarter of the height of the succeeding $R$ wave. The $T$ wave was inverted in four, and incorporated in the RS-T segment in a further three. Bizarre artefacts were a common feature of the œsophageal tracings in this group.

We concluded that although inversion of the $T$ wave may occur and artefacts may render interpretation difficult, the appearances are not likely to be mistaken for those of infarction, since no abnormal $Q$ waves are produced by left ventricular hypertrophy.

Back-Foot lead $(B F)$. In 8 of the 28 normal subjects, a $Q$ wave was present in lead BF but the maximum depth was only $1 \mathrm{~mm}$., and in no case did the depth exceed one-quarter of the succeeding $R$ wave, nor the duration $0.04 \mathrm{sec}$. The $T$ wave was isoelectric in two cases, but never inverted, and there was positive deviation of the RS-T segment in 11 cases.

Of the 27 examples of posterior infarction, a $Q$ wave was present in 22 , the average depth being $3 \mathrm{~mm}$. In 18 of these it was $0.04 \mathrm{sec}$. or more in duration, and in 20 the depth was onequarter or more of the height of the succeeding $R$ wave. The $T$ wave was inverted in 19 of the 27 cases. It was isoelectric or diphasic in the remainder, except for two cases in which it was positive.

Lian et al. (1945) conclude that apart from cardiac infarction, the $T$ wave in lead BF is only exceptionally inverted. It was negative in 47 per cent of their series with posterior infarction. Tourniaire et al. (1948) found it to be inverted in three-quarters of cases of cardiac pain with TIII type curves, but stated that inversion in this lead could also occur as a result of positional change, particularly in the presence of right axis deviation, a fact that detracts from its diagnostic value in posterior infarction. As previously stated, it was not inverted in our normal controls, and our figure of 70 per cent inversion in the posterior infarct series is in agreement with that given by Tourniaire et al. in their investigation of both normal cases and those with posterior infarction. Using a similar lead, Wood et al. (1933) came to the conclusion that its variations, were similar to those of lead III. Table I shows a close correspondence between the findings in leads VF and BF in both the normal and posterior infarction cases. We therefore conclude that lead BF contributes 
no information that cannot be obtained from the more common leads III and VF and it has the disadvantage of requiring the application of an interscapular electrode to an ill patient.

Deep Epigastric lead $(D E)$. We hoped that by pressing the exploring electrode deep into the epigastrium it could be brought to face the inferior surface of the heart. In practice, owing to obesity or lack of muscular relaxation this was usually impossible. Wolferth et al. (1943) and Helm et al. (1944) as a result of detailed cardiographic exploration of the body surface, agree that the præcordial pattern and not the diaphragmatic pattern of potential is distributed to the upper abdomen above the umbilicus. Our deep epigastric recordings, although variable, were mainly of this præcordial type. It would thus appear to be a valueless lead in the diagnosis of posterior cardiac infarction.

\section{Discussion}

When lead III shows a $Q$ wave with an inverted $T$ wave it is necessary to determine whether this is due to posterior infarction or merely to a transverse position of the heart. The appearance of lead III in both cases can be identical. As is well known, further support can be obtained from lead II, but if this lead is within normal limits, and it may be so in posterior infarction (Nyboer, 1941), then appeal must be made to other leads. Several other leads have been recommen'ded and from them we have investigated the following, namely, VF, BF (back-foot), deep epigastric, and gastro-œsophageal leads.

The use of the œsophageal lead need not be seriously unpleasant; we failed in 13 of 150 cases. The importance of ascertaining the position of the electrode in the œsophagus or stomach by fluoroscopy is stressed. Unfortunately this necessitates the attendance of a doctor and the patient must be well enough to stand.

The varied opinions as to the diagnosis of posterior infarction in standard and unipolar leads is the reason for this investigation of other leads. As regards lead III, the larger the $Q$ wave in relation to the $\mathrm{R}$ wave the more likely is it to be due to disease. The significant proportion of the $Q$ wave to the $R$ wave has varied, usually from one-quarter to one-half. Pardee (1930) considered that if the $Q$ wave in lead III was one-quarter of the maximum excursion of the QRS complex, in whichever lead that occurred, there would be little danger of applying the term abnormal to a $Q$ wave that was really normal. He was the first to state that it would seem that the larger the $Q$ wave in relation to the voltage of QRS, the closer the association of coronary narrowing would be. Durant (1934) stated that a $Q$ wave of more than one-half of the height of $R$ was almost always abnormal. In the same year Lian (1934) stated that, although it was rare, the condition where the depth of $Q$ is equal to the height of the succeeding $R$ wave is diagnostic of infarction. By 1938 Chavez and Mendez were willing to accept a $Q$ wave of one-third of the highest $R$ wave.

The presence of a $Q$ wave in lead II is of additional significance (Wallace, 1934; and Bayley, 1939). The difficulty has always been in distinguishing the $Q$ and negative $T$ of the transverse heart. We thought at one time with Lyle (1944) that the disappearance of Q on full inspiration was proof that it was merely due to the position of the heart, but we have met with exceptions; the $Q$ of infarction can disappear on full inspiration.

With regard to lead VF the same criteria have been applied. Myers and Oren (1945) think $Q$ must exceed a quarter and Goldberger (1945) requires it to exceed a half of $R$, and its duration to be $0.04 \mathrm{sec}$. or more.

Similar criteria have been applied to the gastro-œsophageal leads. Myers and Oren (1945) state that the $Q$ wave is abnormal if it equals or exceeds $0.4 \mathrm{~mm}$., or one-quarter of the $R$ wave in the same lead, and Nyboer (1946) accepts similar findings, except that he says that the Q wave should not equal or exceed one-fifth of the $R$ wave.

For our purposes we have held the view that duration and size must both be taken into account; duration must equal or exceed $0.04 \mathrm{sec}$., as measured from the top of the base line; and the depth 
must exceed one-quarter of $R$ measured from the bottom of the base line to its nadir; the $T$ wave must in addition be sharply inverted. When we compared the standard leads of the 27 infarction cases with the gastro-œsophageal records, we found that by the above criteria 24 standards were pathological as against 23 . In the group of 42 cases with classical cardiac pain and dubious standard leads, VF revealed posterior infarction in 18, but the csophageal leads showed it in only 11 of these. In 19 cases without pain, but with a doubtful lead III, VF showed three infarcts and the osophageal leads four. There was no suggestion of infarction in the ten cases of hypertrophy of the left ventricle either in VF or œsophageal leads.

\section{SUMMARY}

From our investigation of standard leads II and III, lead VF, lead BF, the deep epigastric lead, and gastro-œsophageal leads at six levels, we conclude that the lead most likely to confirm or disprove the presence of a posterior infarct, when the standard leads II and III are equivocal, is lead VF. This is slightly superior to the gastro-œsophageal leads for this purpose, although gastro-œsophageal leads are the next most likely to be of value when doubt exists. The back-foot lead (BF) is less satisfactory than œsophageal leads. The deep epigastric lead is valueless.

In view of the slight superiority of lead VF over gastro-œsophageal leads, and the disadvantages of the latter, such as the unpleasantness to the patient, the necessity for direct fluoroscopic control, the frequent occurrence of artefacts, the close resemblance between normal transitional zone records and pathological ventricular level tracings, and the fact that the electrode may at times be in juxtaposition to the right ventricle instead of the left, there would appear to be no case for the employment of œsophageal leads in the diagnosis of posterior cardiac infarction.

\section{REFERENCES}

Bain, C. W. C. (1950). Brit. Heart J., 12, 431.

Bayley, R. H. (1939). Amer. Heart J., 18, 308.

Brown, W. H. (1936). Amer. Heart J., 12, 1.

Burchell, H. B. (1948). Amer. J. med. Sci., 216, 492.

Chavez, I., and Mendez, L. (1938). Arch. Ma!. Coeur, 31, 897.

Cremer, M. (1906). Münch. med. Wschr., 53, 811.

Deglaude, L., and Laubry, P. (1939). Arch. Mal. Coeur, 32, 121.

-, (1949. Arch. Mal. Coeur, 42, 861.

Durant, T. M. (1934). Amer. J. med. Sci., 188, 225.

Goldberger, E. (1945). Amer. Heart J., 30, 341.

(1949). Unipolar Lead Electrocardiography, 2nd ed. Henry Kimpton, London.

Helm, J. D., Helm, G. H., and Wolferth, C. C. (1944). Amer. Heart J., 27, 755.

Katz, L. N., (1950). Circulation, 2, 106.

Kistin, A. D., Brill, W. D., and Robb, G. P. (1950). Circulation, 2, 578.

Lian, C. (1934). Bull. Soc. med. Hôp. Paris, 50, 24.

- Faquet, J., Welti, J. J., and Chadoutaud (1945). Arch. Mal. Coeur, 38, 89.

Lyle, A. M. (1944). Amer. Heart J., 28, 199.

Myers, G. B., and Oren, B. G. (1945). Amer. Heart J., 29, 708.

Nyboer, J. (1939). J. Clin. Invest., 18, 495.

(1941). Amer. Heart J., 22, 469.

(1946), Trans. Life Insur. med. Dir. Amer., 30, 31.

Pardee, H. E. B. (1930). Arch. intern. Med., 46, 470.

Scherlis, L., Sandberg, A. A., Wener, J., Master, A. M., and Grishman, A. (1950). Circulation, 2, 598.

Tourniaire, A., Blum, J., Guyot, R., and Deyrieux, F. (1948). J. méd. Lyon, 29, 25.

Wallace, A. W. (1934). Amer. J. med. Sci., 188, 498.

Wolferth, C. C., Livezey, M. M., and Wood, F. C. (1943). Amer. J. med. Sci., $205,469$.

Wood, F. C., Bellet, S., McMillan, T., and Wolferth, C. C. (1933). Arch, intern. Med., $52,752$. 